\title{
Evaluation of Intensivist-Nurses' Knowledge Concerning Medication Administration Through Nasogastric and Enteral Tubes
}

\author{
Maria Lurdemiler Sabóia Mota ${ }^{1}$ \\ Islene Victor Barbosa ${ }^{2}$ \\ Rita Mônica Borges Studart ${ }^{3}$ \\ Elizabeth Mesquita Melo 4 \\ Francisca Elisângela Teixeira Lima ${ }^{5}$ \\ Fabíola Amaro Mariano ${ }^{6}$
}

This study evaluates the knowledge of nurses working in intensive care units concerning recommendations for the proper administration of medication through nasogastric and enteral tubes. This exploratory-descriptive study with a quantitative approach was carried out with 49 nurses in an intensive care unit of a tertiary hospital in Fortaleza, CE, Brazil. A total of $36.7 \%$ of nurses reported they disregard the dosage forms provided by the pharmacy at the time of administering the medication through tubes. Metal, wood, or a plastic mortar is the method most frequently reported (42.86\%) for crushing prescribed solid forms; $32.65 \%$ leave the drugs in $20 \mathrm{ml}$ of water until dissolved; $65.3 \%$ place the responsibility for choosing the pharmaceutical formulation and its correlation with the tube site, either into the stomach or into the intestine, on the physician. The results indicate there is a gap between specific literature on medication administered through tubes and knowledge of nurses on the subject.

Descriptors: Nursing; Pharmaceutical Preparations; Enteral Nutrition.

\footnotetext{
${ }^{1}$ RN, Ph.D. in Pharmacology, Assistant Professor, Universidade de Fortaleza, CE, Brazil. E-mail: mila269@terra.com.br.

${ }^{2}$ RN, Doctoral Student, Universidade Federal do Ceará, CE, Brazil. Professor, Universidade de Fortaleza, CE, Brazil. E-mail: islene@terra.com.br.

${ }^{3}$ RN, M.Sc. in Nursing, Professor, Universidade de Fortaleza, CE, Brazil. E-mail: monicastudart@hotmail.com.

${ }^{4}$ RN, Ph.D. in Nursing, Professor, Universidade de Fortaleza, CE, Brazil. E-mail: elizjornet@yahoo.com.br.

${ }^{5}$ RN, Ph.D. in Nursing, Adjunct Professor, Universidade Federal do Ceará, CE, Brazil. E-mail: felisangela@yahoo.com.br.

${ }^{6}$ RN. E-mail: bernalmeda@yahoo.com.br.
}

Corresponding Author:

Elizabeth Mesquita Melo

Universidade de Fortaleza

Av. Washington Soares, 1231, Bloco C, Sala 04

Bairro Edson Queiroz

CEP: 60810-300 Fortaleza, CE, Brasi

E-mail: elizjornet@yahoo.com.br 


\title{
Avaliação do conhecimento do enfermeiro de unidade de terapia intensiva sobre administração de medicamentos por sonda nasogástrica e nasoenteral
}

O estudo objetivou avaliar o conhecimento do enfermeiro de unidade de terapia intensiva sobre as recomendações para a correta administração de medicamentos, por sondas nasogástrica e nasoenteral. Estudo exploratório-descritivo, com abordagem quantitativa, realizado com 49 enfermeiros em uma unidade de terapia intensiva de um hospital terciário, localizado na cidade de Fortaleza, no Estado do Ceará, Brasil. Dos enfermeiros, $36,7 \%$ relataram não dar atenção às formas farmacêuticas disponibilizadas pelo setor de farmácia na hora da utilização por sonda. O pilão de metal, madeira ou plástico foi o método mais referido $(42,86 \%)$ para triturar as formas sólidas prescritas. Sendo que $32,65 \%$ costuma deixar os fármacos em $20 \mathrm{~mL}$ de água até dissolver, 65,3\% atribuem ao médico a responsabilidade sobre a decisão da formulação farmacêutica e a correlação com a localização da sonda no trato gastrointestinal. Os achados apontam para diferença entre a literatura específica para medicamentos administrados por sonda e o conhecimento de enfermeiros sobre o assunto.

Descritores: Enfermagem; Preparações Farmacêuticas; Nutrição Enteral.

\section{Evaluación del conocimiento del enfermero de terapia intensiva sobre administración de medicamentos por sonda nasogástrica y nasoentérica}

\begin{abstract}
El objetivo del estudio fue evaluar los conocimientos del enfermero de la unidad de cuidados intensivos sobre las recomendaciones para la correcta administración de medicamentos por sonda nasogástrica y nasoentérica. Se trata de un estudio exploratorio-descriptivo y cuantitativo con 49 enfermeros en una unidad de cuidados intensivos de un hospital terciario, en la ciudad de Fortaleza, estado de Ceará, Brasil. 36,7\% no prestan atención a las formas disponibles en el sector de farmacia en el momento de su utilización por sonda. El pilón de metal, madera o plástico fue el método más citado (42,86\%) para triturar las formas sólidas prescritas. $32,65 \%$ dejan los fármacos en $20 \mathrm{~mL}$ de agua hasta que se disuelvan. $65,3 \%$ atribuyen al médico la responsabilidad de decidir sobre la formulación y la correlación con la ubicación de la sonda en el tracto gastrointestinal. Los resultados indican que hay una diferencia entre la literatura para los medicamentos administrados por sonda y el conocimiento de los enfermeros sobre el tema.
\end{abstract}

Descriptores: Enfermería; Preparaciones Farmacéuticas; Nutrición Enteral.

\section{Introduction}

The administration of medication is a complex process that implies the participation of three professionals: physician, pharmacist and nurse. In Brazil, the nursing team has the responsibility of preparing and administering medication and for follow-up of the medication's effects on patients.

This practice is supported by the Decree 94,406/87 that regulates nursing practice. According to this Decree, the administration of medication is the responsibility of nurses even when actually performed by another member of the nursing team ${ }^{(1)}$.

Gavage feeding consists of inserting a narrow tube via the nose through the esophagus into the stomach or intestine to provide enteral nutrition and medication to patients who cannot swallow ${ }^{(2)}$.

To appropriately administer medication through digestive tubes, one needs to have knowledge concerning the characteristics of different drug dosage 
forms available in the market, the possibility of using or not using them, and the respective correct handling technique ${ }^{(3)}$.

Crushing solids before administering them may present various problems, especially when crushing changes the medication's pharmacokinetics and pharmacological action(4). It is worth highlighting that some dosage forms are unsuitable for tubes or enterostomy administration. Despite the frequency with which patients require medication administration via enteral tubes, drugs are not always available in liquid form and, consequently, crushing solids is a technique that is used, though it does not ensure patients' safety ${ }^{(5)}$. Drugs formulated for oral administration undergo different processes of biotransformation: release, absorption, distribution, metabolism and excretion. When an individual changes the oral solid dosage form of certain medications, one of the these processes may be altered(6).

The rational use of medication includes the correct use of administration routes and consequently, good nursing care. Any medication rationally used becomes an essential tool for the effective control of pathologies and full knowledge concerning its actions by all the professionals who compose the nursing team is essential.

There have been studies addressing medications ${ }^{(7)}$, though with little emphasis on administration via nasogastric and nasoenteral tubes. Hence, this study contributes to the dissemination of knowledge not consolidated previously, enabling the reduction of drug interactions and promoting improved performance by the nursing team. This study evaluates the knowledge of nurses working in Intensive Care Units (ICU) concerning recommendations for the correct administration of medication through nasogastric and nasoenteral tubes.

\section{Method}

This exploratory descriptive study with quantitative approach aims to develop, clarify and improve concepts related to the problem. Exploratory investigations allow researchers to acquire an overview of the investigated matter(8).

The study was carried out in a specialized public university hospital in Fortaleza, CE, Brazil. The facility is a center of excellence in health care and care for patients with various levels of complexity and has three ICUs for adults with diverse pathologies. The study's population consisted of 62 nurses who worked in the three ICUs. The sample was composed of 49 nurses working at the time of data collection. Professionals who did not consent to participate in the study or did not return the questionnaire were excluded from the study.

The application of the questionnaire occurred over 120 consecutive days, beginning in November 2008 after the Research Ethics Committee at the hospital approved the project (Protocol n091002/08).

The variables considered in the evaluation of nurses knowledge concerning the administration of medication through tubes were complicating factors for the use of this route: the study catalogues pharmacokinetic changes as consequence of crushing solids, potential damage to the gastrointestinal tract, and makes recommendations for the correct manipulation of medication and tubes. Descriptive statistics (average and percentage) were applied using Epi-Info in order to analyze data; the data were then presented in tables.

\section{Results}

Of the study's participants: 51\% (25) reported working in ICUs more than five years and 49\% (24) less than five years.

Table 1 - Distribution of nurses according to basic technical knowledge of pharmaceutical formulation. Fortaleza, CE, Brazil 2009

\begin{tabular}{|c|c|c|}
\hline Answers & $\mathbf{N}$ & $\%$ \\
\hline Do not take time to observe basic technical details of pharmaceutical formulation, crushing any product dispensed by the pharmacy & 18 & 36.7 \\
\hline Do not believe the dosage form is important for the correct drug action & 17 & 34.7 \\
\hline Appropriately discriminate sustained-release from sustained-action dosage forms & 14 & 28.6 \\
\hline Total & 49 & 100 \\
\hline
\end{tabular}

A total of $36.7 \%$ do not pay attention to dosage forms dispensed by the pharmacy and $34.7 \%$ do not believe dosage forms affect a drug's action. 
Table 2 - Distribution of nurses according to answers concerning means used to crush solid forms. Fortaleza, CE, Brazil 2009

\begin{tabular}{|c|c|c|}
\hline Answers & $\mathbf{N}$ & $\%$ \\
\hline Drugs are crushed with a metal, wood or plastic mortar & 21 & 42.86 \\
\hline The drug is left in $20 \mathrm{~mL}$ of water until it dissolves & 16 & 32.65 \\
\hline The drug is crushed within its own wrap or waxed paper with a rounded edge weight & 12 & 24.49 \\
\hline Total & 49 & 100 \\
\hline
\end{tabular}

This item did not address medication prescribed to be administered via tube, rather it addressed information on methods used for crushing the drugs. Metal, wood or plastic mortar was the most reported (42.86\%) method, though some nurses (32.65\%) still leave drugs in water for it to dissolve.

Table 3 - Distribution of nurses according to answers concerning the importance of locating the tube in the stomach or intestine for infusing solid dosage forms. Fortaleza, CE, Brazil 2009

\begin{tabular}{|c|c|c|}
\hline Answers & $\mathbf{N}$ & $\%$ \\
\hline $\begin{array}{l}\text { I believe that when the physician prescribes it, s/he already considers whether the medication should be administered into } \\
\text { the stomach or the intestine }\end{array}$ & 32 & 65.3 \\
\hline It makes no difference whether the tube is in the stomach or intestine & 12 & 24.50 \\
\hline I always want to make sure the type of medication is correlated with the tube position & 5 & 10.20 \\
\hline Total & 49 & 100 \\
\hline
\end{tabular}

Most of the professionals (65.3\%) grant the worrying that $24.50 \%$ of the sample holds the view that physician the entire responsibility of knowledge and the site where the tube is inserted makes no difference. decision-making concerning medication absorption. It is

Table 4 - Distribution of nurses according to answers concerning the infusion of solid forms through tubes. Fortaleza CE, Brazil 2009

\begin{tabular}{|c|c|c|}
\hline Answers & $\mathbf{N}$ & $\%$ \\
\hline All the drugs scheduled for the same time are administered at the same time through the same syringe & 25 & 51.0 \\
\hline Drugs are crushed at least 30 minutes before administration and the tube is not washed between administrations & 15 & 30.7 \\
\hline $\begin{array}{l}\text { Each drug is individually administered, crushed immediately before its administration and individually diluted and } \\
\text { administered; the tube is washed between medication administrations }\end{array}$ & 9 & 18.30 \\
\hline Total & 49 & 100 \\
\hline
\end{tabular}

We note that $51 \%$ of the sample administers the drugs scheduled for the same time, at the same time with the same syringe.

Table 5 - Distribution of recommendations considered important for the administration of solid dosage forms with tubes. Fortaleza, CE, Brazil 2009

\begin{tabular}{|c|c|c|}
\hline Recommendations & $\mathbf{N}$ & $\%$ \\
\hline Prepare each medication separately & 28 & 57.10 \\
\hline Preferably use liquid dosage forms and dilute them in 10 to $20 \mathrm{~mL}$ of water & 22 & 44.90 \\
\hline Tablets should be crushed, without using hard blows, until a fine powder is obtained and then dissolved in $10-20 \mathrm{~mL}$ of water & 37 & 75.51 \\
\hline $\begin{array}{l}\text { In general, granules contained in capsules should not be crushed because their formulations may contain a specific coat for } \\
\text { enteral releasing of the active principle }\end{array}$ & 18 & 36.73 \\
\hline Solid dosage forms, sustained-release and sublingual dosage forms should not be crushed & 14 & 28.57 \\
\hline
\end{tabular}


Table 5 indicates that nursing practices concerning this subject should be reevaluated since only 14 (28.57\%) nurses recommended that solid dosage forms, sustained-release, and sublingual tablets or capsules should not be crushed.

\section{Discussion}

No significant differences were found among nurses concerning the length of their time of work in the ICU. This study investigated possible inferences from the data or correlations with practices rooted in unscientific foundations.

The specificity of the work in ICUs contributes to nurse stress and frequently leads nurses to deviate from technically sound practice, which might be associated with the fact that critical patients require special care, complex interventions, uninterrupted care and generally, immediate care, which is different from care provided in other non-critical units ${ }^{(9)}$.

The study's participants do not value knowledge related to dosage forms. This fact might be associated with a deficient academic education, specifically in relation to medication, which does not address items related to medication administration techniques. This is alarming and at the same time indicates that educational issues related to medication administration techniques need to be reevaluated. Basic general knowledge concerning medication should be universalized for the safety of patients.

A significant percentage (36.7\%) of nurses disregard dosage forms provided by the pharmacy. This is a relevant fact, especially if work with medication should be taken as a process with multiple participants whose responsibility is to properly continue the work of the others in order to detect errors and ensure the safety of patients and therapeutic success.

Many considerations should be taken into account before starting any pharmacological therapy via enteral tubes, which might become a problem considering the lack of information available in the literature and limited information provided by manufacturers. Many drugs were not developed to be administered via enteral tubes and many recommendations are based on empiricism(10).

Few nurses (28.6\%) appropriately discriminate between sustained-release and sustained-action dosage forms. Regular tablets are those that can generally be crushed, but sustained-release and sustained-action tablets should not be crushed since they have a coating - the mixture of granules dissolves at different intervals and there are special matrices that are inert, slowing the release of the drug(11).

The dosage form of a medication represents its physical form (tablet, capsule, suspension, pills, syrup, suppository). Each form presents its own characteristics and specific sites for the body to correctly absorb the medication. Currently, there are drugs (capsules, sublingual tablets, coated tablets and pills) that cannot suffer alterations in their initial conditions. They cannot be crushed to be administered via tubes because they are inappropriate for such use, hence an alternative form or administration route has to be selected ${ }^{(9)}$.

In relation to the instruments used to crush solid forms, metal, wood or plastic mortar was the most reported $(42.86 \%)$. This fact is important because: 1 ) there is a potential loss of fragments of the medication that may be trapped onto these instruments; 2) there are potential interactions between the prescribed dosage form with the mortar material (e.g. metal); and 3) there are potential drug interactions as a consequence of not washing the mortar between the crushing of multiple drugs.

Various nurses reported that they leave drugs in $20 \mathrm{~mL}$ of water until dissolved $(32.65 \%)$. The problem of this technique is the time elapsed until the drug is completely dissolved. If, on the one hand, the chemical structure of the medication is preserved by less manipulation, on the other hand, the medication is more exposed to environmental conditions such as light, heat and diverse microorganisms ${ }^{(11)}$. The amount of the active ingredient by dosage form depends on each level and individual process, on the dynamics of dissolving, absorbing, distributing the medication inside the body and its elimination. The technique of administering oral medication through enteral tubes basically consists of dissolving its content in water for later administration ${ }^{(12)}$.

The administration of oral medication through nasogastric and nasoenteral tubes changes the drug's bioavailability and a certain number of interactions may occur. It is necessary to know and respect each therapy and its administration mode. According to the same authors, there are solid oral dosage forms that should not be crushed such as those with gastric and/or enteric coatings, controlled release, sublingual administration, coatings to cover bad taste or aggressive drugs, drugs sensitive to light or humidity, potential carcinogenic drugs, effervescent tablets, and soft gel capsules with liquid inside (13). 
Solid dosage forms should not be crushed. When necessary, drugs should be crushed inside their own wrap or paper resistant to friction, using a rounded tip weight avoiding hard blows to avoid damaging the drug's chemical structure(14). This manipulation mode was reported by $24.49 \%$ of the interviewees.

When asked about the correlation between the portion of the gastrointestinal tract where the tube is inserted and the type of dosage form to be administered, most of the nurses relied on a physician for related knowledge and decisions. It is important to emphasize that medication administration is multiprofessional, and responsibility should be shared so safety is ensured in the use of each drug.

Pharmacological issues are important when considering the portion of the gastrointestinal tract where the tube should be positioned. A very frequent problem is pharmacokinetic alteration of the prescribed drug. Absorption occurs when the drug is transferred from its administration site to the action site. A drug orally administered needs to be first absorbed by the stomach and intestine but this process might be restricted by the drug characteristics and its physical-chemical proprieties. Bioavailability depends on the anatomical structure in which absorption occurs. Other anatomic, physiological and pathological factors may influence bioavailability and the choice of a drug administration route should be based on knowledge concerning these conditions ${ }^{(15)}$. Hence, it is important to investigate in which portion of the gastrointestinal tract (stomach or intestine) the drug has the greatest absorption, verifying therefore, whether the position of the tube contributes or harms its absorption.

Damage in the form of lesions (ulcers) in the gastrointestinal tract may occur due to the physicalchemical characteristics of the crushed and dissolved dosage form. Osmolarity and $\mathrm{pH}$ conditions should be considered for each drug. Basic solutions should be administered with caution in enteral tubes and acid solutions in the stomach. If there is any contraindication, the physician should consider possible medication loss and adjust the dose ${ }^{(11)}$.

When various drugs have to be administered through a tube, they should be separately administered. However, avoiding this situation is advisable, since drug interactions may occur. The drugs should be administered separately and the probe should be washed with at least $10 \mathrm{~mL}$ of water between each administration ${ }^{(16)}$.

Another important aspect to consider is that some individuals $(30.7 \%)$ in the sample report they crush the drug at least 30 minutes before administering it and do not wash the tube when administering another drug.

Many drugs are stable in dry environments but may become hydrolyzed in humid sites and in aqueous or hydroalcoholic solutions. Hence, the stability of solid dosage forms in aqueous solutions can be altered with a consequent reduction of pharmacological action. The frequency with which the tube is washed is another important aspect to analyze because of potential drugdrug and drug-probe interactions ${ }^{(17)}$.

Nurses have the primary responsibility of administering medication and caring for the tubes. The knowledge of these professionals concerning the techniques used directly influences therapy results.

As a crucial aspect in the evaluation of the nurses' knowledge concerning the administration of medication through tubes, they were asked to take a pre-developed list and check aspects they considered relevant for the correct use of medication and tubes as a route to administrate them. All the procedures listed were correct according to the literature.

A total of 119 recommendations with an average of 2.5 recommendations by nurses were identified. Because all the statements were correct, this leads to the conclusion that the nurses' knowledge is, on average, poor in relation to medication administration.

Discussing the subject of medication administration is essential when one tries to minimize complications inherent to this nursing activity. Studies emphasize the importance of improving the nursing team's knowledge on medication administration, including dosage action and calculation, considering the environment where medication is prepared and material available. Additionally, nurses should consider potential drug interactions when administering medication(18-20).

It is important to re-evaluate the academic pharmacological education of nurses, since there is probably some difficulty in understanding basic medication administration aspects that can interfere with the pharmacological actions of prescribed drugs and threaten the safety of patients during medication.

\section{Conclusions}

The gap between theory concerning medication administration through tubes and nurse knowledge is a concern due to the fact that crushing sustained-release tablets destroys the drug's properties resulting in erratic blood levels with the risk of increased or diminished drug absorption. 
Using metal, wood or plastic mortars is the most reported method for crushing solid forms. Interactions between the components of the dosage forms and the mortar material, or drug interactions due to not cleaning the mortar between crushing different drugs, may occur.

Most of the nurses studied expect the physician to assume the entire responsibility for the type of dosage form and for correlating the dosage form with the correct tube site in the gastrointestinal tract.

Drugs scheduled at the same time are generally administered at the same time with the same syringe. The mixing of drug preparations is a factor that triggers drug interactions, can obstruct the tube and generate other problems.

Studies are needed to update nurses on this subject and prevent problems related to the administration of drugs through tubes. The development of protocols can contribute to the correct selection of the drug dosage form and administration technique and evaluate incompatibilities and interactions.

\section{References}

1. Conselho Regional de Enfermagem-Coren (BR-SP). Principais legislações para o exercício da enfermagem. São Paulo: COREN; 1996.

2. Dopico LS, Pereira SEM, Mesquita AMF. Procedimentos de enfermagem - semiotécnica para o cuidado. Rio de Janeiro: MEDSI; 2004.

3. Catalán E, Padilla F. Fármacos orales que no deben ser triturados. Enferm Intensiva 2001; 12(3):146-50.

4. Goñi Viguria R, Sánchez Sanz L, Baztán Indave A, Asiain Erro MC. Administración de fármacos por sonda digestiva. Enferm Intensiva 2001; 12(2):66-79.

5. Magalhães A, Almeida T. Nutrição entérica, interacção fármaco/nutriente. Farmácia Portuguesa 1997; 107:43-7.

6. Mitchell JF. Oral solide dosage forms that should not be crushed: 1996 revision. Hosp Farmacie 1996; 21:27-37.

7 Telles Filho PC, Praxedes MFS. Periódicos de enfermagem e administração de medicamentos: identificação e categorização das publicações de 1987 a 2008. Rev. Latino-Am. Enfermagem 2009; 17(5)721-9.

8. Gil AC. Métodos e técnicas de pesquisa social. 5. ed. São Paulo: Atlas; 2002.

9. Gomes GC, Lunardi WD, Erdmann AL. O sofrimento psíquico em trabalhadores de UTI interferindo no seu modo de viver a enfermagem. Rev Enferm UERJ. 2006; 14(1):93-9.

10. Thomson FC, Naysmith MR, Lindsay A. Managing drug therapy in patients receiving enteral and parenteral nutrition. Hosp Pharm. 2000;7(6):155-64.

11. Bradnam V, White R. Handbook of Drug Administration via Enteral Feeding Tubes. London: RPS Publishing of Royal Pharmaceutical Society of Great Britain; 2007.

12. Beckwith MC, Feddema SS, Barton R, Graves C. A guide to drug therapy in patients with enteral feeding tubes: dosage form selection and administration methods. Hosp Pharm. 2004;39(3):225-37.
13. Engle KK, Hannawa TE. Techniques for administering oral medications to critical care patients receiving continuous enteral nutrition. Am J Health Syst Pharm. 1999; 56(14):1441-4.

14. Estivill Pallejá E, Cardona Pera D, Castro Cels I, Bo-nal de Falgàs J. Administración de fármacos por sonda nasogastrica: formas farmaceuticas orales que no deberían ser trituradas antes de su administración. Farm Clin 1988; 5:324-38.

15. Buxton ILO. Farmacocinética e Farmacodinâmica: a dinâmica da absorção, distribuição, ação e eliminação dos fármacos. In: Brunton LL, Lazo JS, Parker KL. Goodman \& Gilman. As Bases farmacológicas da terapêutica. 11a. ed. Rio de Janeiro: McGrawHill Interamericana do Brasil; 2006. p. 1-36.

16. Gandhi T, Seger D, Bates DW. Identifying drug safety issues: from research to practice. Int J Qual Health Care 2000; 12(1):69-76.

17. AHFS Drug Information. Bethesda: American Society of Health-System Pharmacists; 2005. 3778 p.

18. Silva DO, Grou CR, Miasso AI, Cassiani SHDB. Preparo e administração de medicamentos: análise de questionamentos e informações da equipe de enfermagem. Rev. Latino-Am. Enfermagem 2007; 15(5)1010-7.

19. Oliveira RC, Cassiani SHDB. Caracterização da estrutura para o preparo de medicamentos em hospitais de ensino: fatores que interferem na qualidade da assistência. Rev. Latino-Am. Enfermagem 2007; 15(2)224-9.

20. Lima REF, Cassiani SHDB. Interações medicamentosas potenciais em pacientes de unidade de terapia intensive de um Hospital Universitário. Rev. Latino-Am. Enfermagem 2009; 17(2)222-7. 